\title{
A Case of Isolated Plasmacytoid Lymphoma Presenting as Hard Palate Mass: A Case Report
}

\author{
Parul Bhardwaj $^{1}$, Shivbrat Sharma ${ }^{2}$ \\ ${ }^{1}$ MD Internal Medicine, Civil Hospital Dehra (H.P), ${ }^{2}$ Junior Resident ENT, DRPGMC Kangra at Tanda (H.P) \\ Corresponding Author: Shivbrat Sharma
}

\begin{abstract}
Plasmablastic lymphoma (PBL) is classified under the category of 'Mature B-cell neoplasms'. Plasmablastic lymphomas are the most common and account for $30 \%$ of all the cases type. PBL is an uncommon B-cell tumor which is limited to the jaw and oral cavity at presentation but can spread to distant sites at later stages type. Here we case report a 35 year old male presented to OPD as hard palate mass which turns to plasmablastic lymphoma after investigation.
\end{abstract}

Keywords: Plasmablastic Lymphoma (PBL), Triglycerides (TG), Low density lipoproteins $(L D L)$.

\section{INTRODUCTION}

Lymphomas originate as somatic mutations in lymphocyte progenitor cells (B-cells, T-cells, or both) and are classified as Hodgkin's and non-Hodgkin's lymphomas. According to WHO 2016 revised classification of lymphoid neoplasms, Plasmablastic lymphoma (PBL) is classified under the category of 'Mature B-cell neoplasms' ${ }^{1}$.

Plasmablastic or large B-cell lymphomas are the most common type and account for $30 \%$ of all the cases type ${ }^{2}$. They are diffused type of aggressive large B-cell lymphomas. PBL have been reported in the both human immunodeficiency viruspositive and -negative patients and the incidence of PBL is $2.6 \%$ of all the acquired immunodeficiency syndrome (AIDS) associated $\mathrm{NHL}^{3}$. The prevalence of disease-related deaths was $59.6 \%$ in oral NHL and the average mean survival is 14 months, which indicates the aggressiveness of the disease $\mathrm{e}^{4}$. A total of 612 cases have been reported worldwide from 1997 to $2015^{5}$.

Delecluse et al. gave the terminology "Plasmablastic Lymphoma", when they reported 16 cases of unusually presenting lymphomas at as the primary tumor sites in the oral cavity such as gingiva, floor of the mouth, palate and tonsil ${ }^{5}$. It often involves the head-and-neck area with other sites, including the nasal cavity, gastrointestinal tract, bone, skin, soft tissue and lungs ${ }^{6,7}$. PBL is an uncommon Bcell tumor which at presentation limited to the jaw and oral cavity but can spread to distant sites at later stages. Plasmablastic Lymphoma is categorised by WHO under the category of 'Mature B-cell Neoplasms' ${ }^{\prime}$.

\section{CASE REPORT}

35 year old male patient presented in ENT OPD as chief complaints of mass in the mouth for last one month and bleeding from oral cavity for last 1 day. On local examination there was a mass on the right side of hard palate, approximately $3 * 3 \mathrm{~cm}$, hard in consistency, with smooth surface and non-tender (fig1).

On general physical examination there was no other lymphnodal swelling elsewhere in the body. No other palpable lymphnodes were found in the neck. Patient was smoker and did not consume alcohol. His routine investigations like complete haemogram, fasting blood sugar, liver function test, renal function test and chest $\mathrm{X}$ - 
ray were normal. USG Abdomen was done and no organomegaly was found. Patient's $\mathrm{HIV}, \mathrm{HbsAg}$ and anti $\mathrm{HbC}$ were non reactive. Then his CECT neck was done. On CECT neck there was aheterogeneously enhancing soft tissue mass lesion $(3.3 \times 1.8 \times 2.8 \mathrm{~cm})$ involving right sided buccal and gingival mucosa with erosion destruction of maxilla on right side with extension into maxillaryantrum with multiple subcentrimetriclymph node in all neck stations s/o likely malignant etiology (fig.2).

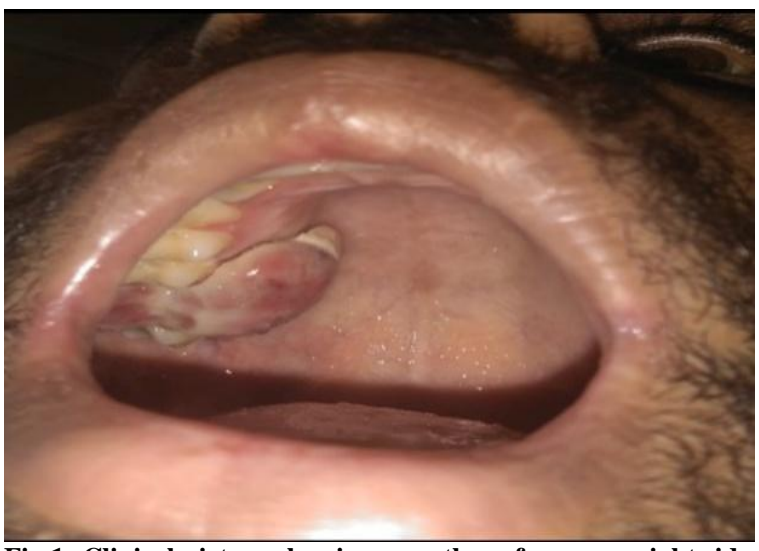

Fig 1: Clinical picture showing smooth surface mass right side hard palate

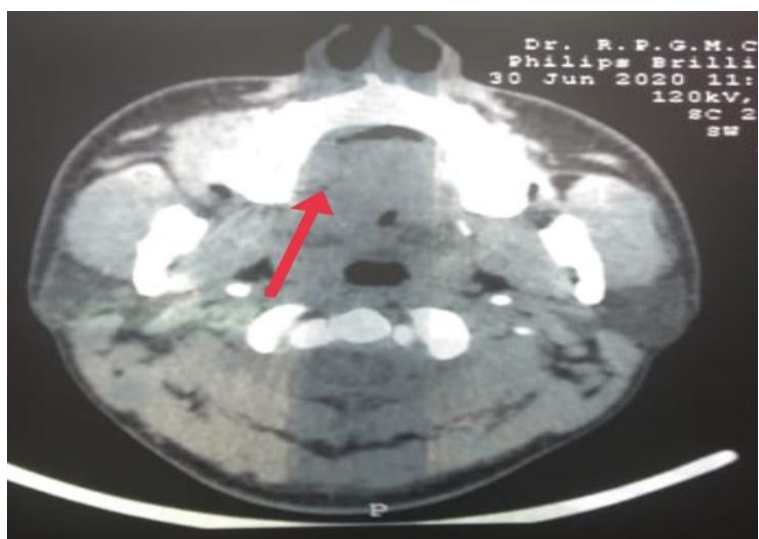

Fig 2: CECT picture showing heterogeneously enhancing leasion in right side hard palate

Then FNAC of mass lesion was done and sent for microscopic examination. On microscopic examination smear comprised of predominantly population of plasmacytoid cells with features suggestive of plasma cell neoplasm. (fig.3)

After FNAC report, patient was referred to higher centre for immunohistochemistry analysis where tumor cells were positive for CD-138, LCA and CD-56.

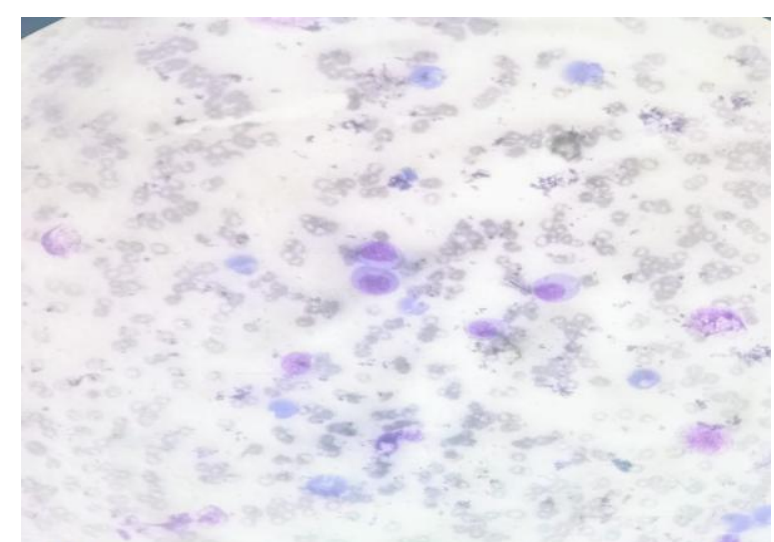

Fig 3: FNAC picture of the lesion showing scattered plasma cells with abormal nuclear cytoplasmic ratio and predominant basophilic cytoplasm.

\section{DISCUSSION}

Delecluse et al. published the first case series of PBL in 1997, in which they described the primary lesions which appeared in the oral cavity without the involvement of the lymph nodes. The primary lesions can be presented with or without infiltration of the surrounding jaw bone in the various sites in the oral cavity and these sites are gingiva, floor of the mouth, palate and tonsils ${ }^{5}$.

Oral NHL can be presented as ulceration, mass lesion, delayed healing of extraction sites or trigeminal neuropathy. It is important to recognize this type of lymphoma confined to gingiva because other gingival enlargements as PBL may mimic benign/reactive gingival enlargements like pyogenic granuloma and peripheral giant cell granuloma?.

The morphological hallmark of plasmablastic lymphoma is diffuse submucosal proliferation of monomorphic large-sized tumor cells with deep ulceration of the overlying mucosa ${ }^{10}$. The tumor cells typically demonstrate high nuclearcytoplasmic ratio, moderate amount of amphophilic, or basophilic cytoplasm with squared or rounded borders and centrally or eccentrically placed round nucleus with smooth nuclear outlines ${ }^{10}$. Plasmablasts are a type of lymphoid cells that have retained the morphology of an immunoblast but have 
already acquired the immunophenotype of a plasma cell ${ }^{7}$. PBL may show plasma cells which are always reactive in nature and never neoplastic.

The prognosis of PBL is reported to be poor with or without treatment but it has been suggested that addition of highly active antiretroviral therapy and chemotherapy is capable of significantly improving the prognosis ${ }^{11}$. The death is predicted in $1-24$ months with average survival time of 6 months ${ }^{11}$.

\section{CONCLUSION}

In conclusion, this paper has detailed the case of plasmablastic lymphoma presented as hard palate mass. So PBL should be considered in differential diagnosis of hard palate mass. FNAC of mass, histopathological examination and immunohistochemical analysis will aid in accurate diagnosis and treatment. Patient was referred to higher centre for further management.

\section{Declaration of Patient Consent}

The authors certify that we have obtained all appropriate patient consent on forms regarding clinical information to be reported in the journal.

\section{Financial Support and Sponsorship: Nil}

Conflicts of Interest: There are no conflicts of interest

\section{REFERENCES}

1. Minges Wols HA. Plasma Cells eLS. 2001:1-1.

2. Eversole LR. Clinical Outline of Oral Pathology: Diagnosis and Treatment PMPH. USA: CBS Publishers and Distributers; 2001.

3. Tilley C. Christopher Dm Fletcher Diagnostic Histopathology of Tumors. Philadelphia: Elsevier Saunders; 2013. p. 2296.
4. Cattaneo C, Facchetti F, Re A, Borlenghi E, Majorana A, Bardellini E, et al. Oral cavity lymphomas in immunocompetent and human immunodeficiency virus infected patients. Leuk Lymphoma. 2005;46:77-81.

5. Delecluse HJ, Anagnostopoulos I, Dallenbach F, Hummel M, Marafioti T, Schneider $U$, et al. Plasmablastic lymphomas of the oral cavity: A new entity associated with the human immunodeficiency virus infection. Blood. 1997;89:1413-20.

6. Harmon CM, Smith LB. Plasmablastic lymphoma: A review of clinicopathologic features and differential diagnosis. Arch Pathol Lab Med. 2016;140:1074-8.

7. Chadburn A, Hyjek E, Mathew S, Cesarman E, Said J, Knowles DM. KSHV-positive solid lymphomas represent an extra-cavitary variant of primary effusion lymphoma. Am J SurgPathol. 2004;28:1401-16.

8. Lin O, Gerhard R, Zerbini MC, TeruyaFeldstein J. Cytologic features of plasmablastic lymphoma. Cancer. 2005; 105:139-44.

9. Desai RS, Vanaki SS, Puranik RS, Giraddi G, and Pujari RV. Plasmablastic lymphoma presenting as a gingival growth in a previously undiagnosed HIV-positive patient: a case report. Journal of Oral and Maxillofacial Surgery. 2007;65:1358-61.

10. Kane S, Khurana A, Parulkar G et al. Minimum diagnostic criteria for plasmablastic lymphoma of oral/sinonasal region encountered in a tertiary cancer hospital of a developing country. Journal of Oral Pathology and Medicine.2009;38:13844.

11. Sarode SC, Zarkar GA, Desai RS, Sabane VS, and Kulkarni MS. Plasmablastic lymphoma of the oral cavity in an HIVpositive patient: a case report and review of literature. International Journal of Oral and Maxillofacial Surgery.2009;38:993-99.

How to cite this article: Bhardwaj P, Sharma S. A case of isolated plasmacytoid lymphoma presenting as hard palate mass: a case report. International Journal of Science \& Healthcare Research. 2021; 6(2): 178-180. DOI: https://doi.org/10.52403/ijshr.20210432 